\title{
Com a bíblia e com o fuzil: notas exploratórias sobre a ascensão evangélica nas forças armadas
}

\author{
Rodrigo Lentz
}

Ana Penido

\begin{abstract}
Resumo: O objetivo deste artigo é explorar possíveis impactos da ascensão evangélica no Brasil em relação a aspectos do Exército como a hierarquia, a disciplina, a sociabilidade, a doutrina, e nas relações com o que os militares chamam de "mundo civil". Para isso, a pesquisa lança mão de dados quantitativos relativos à religião dos cadetes da Academia Militar das Agulhas Negras (2002-2012) e do exame qualitativo da influência religiosa na doutrina da Escola Superior de Guerra (1974-2016). Seus resultados, ainda exploratórios, apontam para mais encontros do que desencontros entre a doutrina militar e a religiosidade evangélica.
\end{abstract}

Abstract: The purpose of this article is to explore possible impacts of the expansion of evangelicalism in Brazil on aspects of the Army such as hierarchy, discipline, sociability, doctrine, and in relations with what the military calls the "civil world". For this, the research uses quantitative data related to the religion of the cadets of the Military Academy of Agulhas Negras (2002-2012) and the qualitative examination of the religious influence in the doctrine of the Escola Superior de Guerra (1974-2016). Exploratory conclusion points to more alignments than mismatches between military doctrine and evangelical religiosity. 
O Censo brasileiro de 2010 confirmou a tendência de crescimento dos evangélicos no Brasil registrada desde a década de 90, mas com uma expressiva novidade: pela primeira vez um grupo religioso não católico apresentou um crescimento acelerado, 61\% em uma década, saltando de 26,2 milhões de pessoas (15,4\% da população) em 2000, para 42,3 milhões (ou 22,2\% dos brasileiros) em 2010 (IBGE, 2012). Dentre os protestantes, o maior grupo, e com tendência ascendente, é o dos pentecostais, cujos fiéis são popularmente chamados de "crentes" ou "evangélicos" (Bohn, 2004; Cunha, 2007). E as projeções são de aumento do crescimento dos evangélicos, com indicação de que em 2040 sejam o maior grupo religioso do país (Cardoso e Miranda, 2020).

Esse fenômeno na América Latina foi alvo de diversos estudos (Giumbelli, 2013; Mariano, 2016; Almeida, 2017; Alencar, 2019; Panotto, 2020). Embora a origem da sua atividade política esteja na década de 1930, apenas no final do século XX os evangélicos acenderam ao poder no Brasil - em especial os pentecostais, uma vez que ocuparam espaços nos poderes legislativos e executivos dos três níveis da administração pública, pautaram a agenda política e se constituíram em importante fração de poder por sua influência em parte considerável do eleitorado (Cunha, 2020; Camurça, 2020; Miguel, Biroli e Mariano, 2017; Prandi e Santos, 2017; Rodrigues e Fuks, 2015; Oro, 2003).

Por sua vez, em 2018, a campanha eleitoral de Jair Bolsonaro (capitão do Exército reformado) e Hamilton Mourão (general de divisão da reserva) demarca o ressurgimento dos militares na esfera pública como atores políticos de grande projeção, embora já houvesse traços anteriores de atuação nos bastidores. Embora não possuam uma legenda formal, muitos quadros vindos do ambiente castrense disputam a hegemonia na arena política brasileira, atuando como principal base de sustentação do presidente e ocupando praticamente a metade dos ministérios (Penido e Lentz, 2020).

A aliança entre as lideranças evangélicas e militares figuram justamente entre as bases primordiais de sustentação da candidatura e do governo Bolsonaro, simbolizadas no slogan de campanha "Brasil acima de tudo, Deus acima de todos". Enquanto o termo "Brasil acima de tudo" representa o apoio do Exército - frase usada como brado da Brigada de Infantaria Paraquedista do Exército (Seto, 2018) - a expressão "Deus acima de todos" expressa a base cristã. Cabe pontuar, Bolsonaro se apresenta como católico e sua esposa é evangélica.

É neste cenário que o presente artigo se propõe a analisar de maneira exploratória as implicações potenciais do crescimento evangélico entre os futuros oficiais do Exército brasileiro. Portanto, não se trata da ascensão política dos evangélicos ou dos militares, mas sim das interfaces entre os dois grupos. Além disso, dizemos exploratórios porque os dados que apontam para o crescimento evangélico nas fileiras militares não especificam adequadamente as denominações praticadas, se evangélicos tradicionais ou pentecostais, pertencentes a grandes ou pequenos templos. Em suma, os dados permitem apenas indicações gerais, relevantes por sua originalidade. 
Assim que a primeira seção do artigo se propõe a apresentar criticamente os dados do crescimento evangélico entre os cadetes da Academia Militar das Agulhas Negras (AMAN). ${ }^{1}$ Em seguida, a segunda seção trata da influência do cristianismo sobre o pensamento político dos militares brasileiros, conforme as mudanças e permanências observadas na doutrina de segurança nacional da Escola Superior de Guerra (ESG) prescrita nos manuais originais editados entre 1974 e 2016 (Comblin, 1980; Oliveira, 1987; Santos, 2010; autor, 2019). ${ }^{2}$ A terceira seção analisa os possíveis impactos do crescimento evangélico dentro de uma Instituição de Estado profundamente marcada pela tradição cristã - o Exército brasileiro - especialmente em aspectos tradicionais como a hierarquia, disciplina e sociabilidade, assim como nas relações com o chamado pelos militares "mundo civil".

\section{Ascenso dos cadetes evangélicos}

Do ponto de vista teológico e da autoidentificação, "evangélicos" é uma denominação excessivamente ampla, por referir-se um grupo bastante heterogêneo, que abrange desde os considerados evangélicos históricos aos neopentecostais. Conforme menciona Mafra (2001), a comunidade evangélica no Brasil se estabelece a partir de 1824, com os imigrantes alemães, em sua maioria luteranos. A partir daí, diversos imigrantes protestantes chegavam ao país, com destaque para as missões estadunidenses de evangélicos luteranos e anglicanos, iniciadas em 1837 e responsáveis por construir uma identidade própria dessa comunidade contextualizada no território.

Já os pentecostais vêm dos EUA e da Suécia para o Brasil na primeira década do século XX. No Brasil, conformaram um segmento cristão teologicamente conservador, com ênfase na piedade pessoal na busca da salvação da alma, sem tradição litúrgica e rígido com os prazeres do corpo (Mendonça, 1990, apud Cunha, 2020, p.23). Os pentecostais só se tornaram hegemônicos entre os evangélicos brasileiros entre os anos 1990 e 2000 (Alencar, 2010; Giumbelli, 2013).

A AMAN percebeu a necessidade de desagregar as denominações evangélicas em 2009, durante o arco temporal dessa pesquisa, mas o alto grau de respostas não especificadas não nos permite ir muito além. Por isso, neste trabalho, empregamos o termo "evangélicos". Para evitar o "fetichismo dos dados" (Castro, 2018, p.11), também é preciso ponderar que esses dados foram produzidos e administrados apenas para fins de cadastro da corporação, e não para pesquisa social.

\footnotetext{
${ }^{1}$ A AMAN é a única porta de entrada para a carreira bélica no Exército Brasileiro, e que possibilita a um oficial atingir o ápice da carreira e o comando da Força. De maneira geral, o Exército possuiu o maior efetivo e a maior relevância política, mas faltam novos estudos comparativos para melhor compreender a dinâmica política da relação entre as três Forças.

${ }^{2} \mathrm{Na}$ escola, de 1948 a 1974, desenvolveu-se e consolidou-se a chamada "doutrina de segurança nacional", que exerceu influência fundamental na formação ideológica da geração de oficiais militares até 1985. A ESG começou a perder espaço político ainda durante o regime dos generais, mas sua doutrina atualizada segue considerada a base do pensamento político dos militares (Bruneau, 2017).
} 
Por exemplo, a declaração quanto à denominação religiosa é feita durante o momento de cadastro dos alunos ingressantes, e nesse sentido, não capturam eventuais mudanças de denominação religiosa ao longo do tempo. Além disso, a amostra se restringe ao corpo de oficiais bélicos, não abarcando o corpo de praças. ${ }^{3}$

Mesmo tendo em conta essas limitações, foi possível perceber o crescimento consistente dos evangélicos e uma redução dos cadetes que professam a religião católica entre os oficiais da AMAN - em proporção superior ao restante da população brasileira, segundo os anuários estatísticos de 2002 a 2012. ${ }^{4}$ Em trabalhos sobre o perfil dos cadetes da AMAN nas décadas passadas, como os de Stepan (1975) e Castro (2004), a variável religiosa estava presente, mas não tinha peso, afinal, havia um amplo predomínio católico na escola, assim como na população brasileira em geral. No entanto, os dados mais recentes apontam uma maior pluralidade de religiões (Penido, 2015).

Na série histórica pesquisada, a queda da religião católica foi significativa, passando de $70 \%$ em 2002 para 54\% em 2012. Manteve-se, contudo, majoritária nas declarações dos cadetes da AMAN. Por seu turno, a religião evangélica representava apenas 14\% em 2002 e, uma década depois, passou a ser a religião declarada de $23 \%$ dos cadetes da AMAN. Note-se que os evangélicos desde o início da série histórica superaram o espiritismo, tradicionalmente a segunda religião entre os militares, e que manteve o terceiro posto com destacada regularidade - de 9\% em 2002 e em 2012, oscilando entre $10 \%$ e $6 \%$ durante a série.

A tendência de crescimento manteve-se na pesquisa de Castro (2018). Os dados desse trabalho apontam para uma média de 29\% de evangélicos durante o período de 2012 a 2014 . Em suma, pode-se afirmar que num intervalo de pouco mais de dez anos, os cadetes que se declaram evangélicos cresceram quase $115 \%$, ou seja, mais que dobraram.

Além disso, a explicação do crescimento evangélico na população pode ser combinada com três hipóteses específicas que acentuam esse crescimento no meio militar (2015). A primeira é o recrutamento de cerca de $70 \%$ dos alunos entre filhos de praças e baixos oficiais - com os menores salários. Em toda a bibliografia a respeito, é inequívoca a afirmação de que as classes altas não cursam, e nunca cursaram, a AMAN. As igrejas pentecostais apontam o mesmo desafio. Embora crescendo tanto numericamente quanto e em reconhecimento social, essas igrejas têm dificuldade para ganhar adeptos entre as classes mais abastadas e escolarizadas brasileiras (Mariano, 2010).

\footnotetext{
${ }^{3}$ Os oficiais bélicos são considerados administradores da violência, executando tarefas estratégicas e de planejamento da Força. Se formam na AMAN, que equivale a um curso de ensino superior. As praças são considerados executores, e têm atividades equivalentes aos níveis fundamental, médio ou técnico. Os problemas advindos da adoção de diferentes denominações religiosas por parte de praças e oficiais já foram decisivos em situações de conflitos hierárquicos dentro exércitos confessionais como é o caso libanês (Cheaito, 2019).

${ }^{4}$ Os anuários estatísticos da AMAN são conjuntos de dados agregados produzidos pela área estatística da escola com informações gerais sobre classe, origem regional, escolaridade, religião, e outros, no intuito de alimentar a área de planejamento e coordenação do Departamento de Ensino do Exército brasileiro.
} 
A segunda hipótese é a queda da endogenia. No período entre 2002-2012, em média de 75\% dos ingressantes tinham origem em estabelecimentos de ensino civis, o que abre a possibilidade para uma maior diversificação religiosa. Por fim, cabe pontuar a origem regional dos cadetes. Segundo Castro (2004), os números do Sudeste da década de 1960 até 2002 sempre ficaram acima de $50 \%$. Boa parte dos cadetes vinha do estado da Guanabara (atual cidade do Rio de Janeiro), pois este também era o estado com a maior concentração militar do Brasil. Os dados de Penido (2015) confirmam e acentuam a tendência de domínio do Sudeste, sendo que entre os estados da região, o Rio de Janeiro responde por mais de $30 \%$ da origem dos cadetes - estado que tem liderado o processe de transição religiosa do país, com 64 evangélicos a cada 100 católicos (Alves, 2019).

\section{“Deus acima de todos": o humanismo cristão na doutrina da ESG ${ }^{5}$}

O Brasil está no rol dos países que adotam o regime de separação entre Estado e Igreja, o Estado laico - sem religião oficial -, mas confere relações assimétricas entre as religiões pelo histórico predomínio católico (Oro e Ureta, 2007). A ascensão pentecostal aos espaços de poder em países latino americanos acentua, portanto, a disputa por influência política até então exercida hegemonicamente pelo catolicismo (Almeida, 2017). Daí que qualquer análise sobre a "relação entre Estado, religião e sociedade nos últimos anos no Brasil seja considerada também uma tentativa de reflexão sobre os impactos da expansão evangélica" (Giumbelli, 2013).

Historicamente, a intimidade entre religião e forças armadas (FA) remete ao período colonial no Brasil, quando da fundação, em 1623, da Irmandade da Santa Cruz dos Militares (ISCM). Enquanto local de profissão da fé católica, também se constituía uma fraternidade que reunia militares da colônia em torno do catolicismo e de atividades de assistência social. Em 1828, depois da independência, a Irmandade foi declarada um "templo imperial" pelo Imperador D. Pedro I e, no centenário da independência (1922), já na República, chegou a realizar um seminário comemorativo sobre "O catolicismo na história do Exército e da Armada Brasileira" (ISCM, 2020). Recentemente, em 2010, foi promulgado acordo entre o Estado brasileiro e o Estado do Vaticano formalizando a institucionalização do "Ordinariado Militar" com suas respectivas Capelanias e Capelães militares (AMB, 2020). ${ }^{6}$

Essa relação tradicional e institucional entre catolicismo e organização militar se manifesta ontologicamente no pensamento político dos militares. Cada força armada tem instituições de

\footnotetext{
${ }^{5}$ Esta seção é uma parte editada da tese de doutoramento do Autor, em fase de defesa.

${ }^{6}$ Segundo a Arquidiocese Militar do Brasil, o Capelão Militar deve ser "Ministro Religioso - Padre, Pastor, etc., com experiência comprovada no Ministério Cristão" e ser aprovado "em concurso público de provas e títulos", quando é matriculado "em curso militar de Estágio e Adaptação de Oficial Capelão" (AMB, 2020). Ainda conforme Arquidiocese, há 229 religiosos residentes em instituições militares no Brasil: a) capelães - 46 no Exército, 38 na Marinha, 20 na Aeronáutica, 31 na Polícia Militar, 7 no Corpo de Bombeiros e 5 capelães-chefes; b) 66 diáconos permanentes; c) e 7 "civis" (Decreto n.7.107, de 11 de fevereiro de 2010).
} 
ensino próprias e com autonomia consolidada, exercendo influência direta na tomada de decisão e comportamento de seus membros, inclusive sobre as possibilidades de ascensão na carreira. Para o Exército, por exemplo, a principal instituição de altos estudos é a Escola de Comando e Estado Maior do Exército (ECEME). Entretanto, essas escolas compartilham de uma base doutrinária comum produzida pela ESG (Farias, 1991).

Desse modo, cabe examinar a presença da religião e do cristianismo nessa doutrina da ESG (a seguir apenas chamada de doutrina) para dimensionar suas implicações estruturais nas instituições militares. Considerando as edições do Manual Básico da doutrina da ESG - publicadas do governo de Ernesto Geisel (1974-1979) ao governo Dilma Rousseff (2010-2014) - são destacados três aspectos presentes em seu núcleo ontológico que se mantiveram perenes: o racionalismo cristão, a dignidade da pessoa humana e a noção de bem comum (Brasil, 1975, 1983, 1988, 1994, 2002, 2005, 2009, 2014).

Nesse passo, foi plenamente preservada a crença primeira da existência de Deus: uma dimensão superior ao Homem, força criadora da totalidade do universo e de seus seres. Embora na edição de 1975 a doutrina se referisse aos valores espirituais do Homem como intransponíveis, foi na edição de 1983 que se verificou o termo expresso "Deus" como o criador, entidade superior e elemento intrínseco à natureza humana, sendo inegável para a doutrina a "existência de uma lei natural e eterna, cuja fonte é Deus, fim para qual tendem os homens" (Brasil, 1983, p.34).

A partir de 1988, a doutrina mantém a subordinação do Homem ao Criador, tendo como consequência uma inata transcendência da natureza humana. Mais especificamente, da natural abertura da pessoa humana a Deus (Brasil, 2014b, p.52; 2009b, p.51; 2006b, p.43; 2002, p.95). Assim, para a doutrina, Deus permanece como princípio fundador, conforme a própria cultura ocidental que "reconhece a presença imanente da divindade no ser humano" (Brasil, 1988, p.22; 2002, p.25; 2006a, p.5-6; 2009a, p.13; 2014a, p.9-10).

Ao longo de todas as edições da doutrina, a natural racionalidade do "Homem" recebeu apenas algumas variações em sua caracterização. Embora, antes de 1988, a doutrina chegasse a se referir à dignidade da pessoa humana como "dotada de razão e livre arbítrio" (Brasil, 1983, p.34), foi a partir da edição de 1988 que o fundamento teísta cristão da racionalidade humana passa a ser mencionado explicitamente. Apesar da "presença imanente da divindade" em si mesmo, o Homem teria plenamente "a capacidade de construir seu próprio destino: dotado de consciência e vontade, o Homem pode ter sempre a possibilidade moral de decidir, superando condicionamentos" (Brasil, 1988, p.22; 2002, p.25). A partir da edição de 2002, observou-se uma mudança, acentuando seu caráter individualista: a superação desses condicionamentos seria "em busca da realização de um projeto de vida individual" (Brasil, 2006a, p.5; 2009a, p.13; 2014a, p.9). Nesse projeto individual de felicidade, o livre arbítrio do "Homem" o tornaria responsável por seus atos, pois a pessoa humana se encontra "Dotada de razão, de consciência de si, de natural abertura ao mundo, aos homens e a 
Deus, de capacidade para distinguir o falso do verdadeiro, o bem do mal, em si e fora de si (consciência moral)" (Brasil, 2014b, p.52-53; 2009b, p.51; 2006b, p.44; 2002, p.95).

Portanto, seria essa capacidade de ter consciência de si e, principalmente, de distinguir o falso do verdadeiro, o bem do mal, e a condição humana da racionalidade. Isso é importante porque, para a doutrina, apesar dos condicionamentos de toda ordem, ao fim e ao cabo, toda a ação humana, por natureza, é movida conscientemente por interesse individual. Antes de 1988, a doutrina descrevia que "em sua vida individual e de relacionamento, os homens experimentam necessidades, materiais e imateriais, inclusive espirituais, que vão despertar ou incrementar seus interesses pessoais" (Brasil, 1975, p.39).

$\mathrm{Na}$ caracterização desses interesses individuais, a doutrina manteve os componentes materiais, culturais e espirituais. Neste caso, depois de suprimir os interesses "espirituais" (Brasil, 1988, p.31), a doutrina retomou a crença em uma "extensa gama de necessidades materiais e de interesses e aspirações de ordem cultural e espiritual" como os fundamentos do agir humano (Brasil, 2002, p.36; 2006, p.12; 2009, p.20; 2014, p.18). Considerando essa significação, a doutrina sustenta que "toda ação racional pressupõe dois elementos básicos: fins a atingir e meios a empregar" (Brasil, 1988, p.17; 2002, p.22; 2006a, p.16; 2009a, p.16; 2014a, p.13). É nesta dimensão, entre fins e meios, que a doutrina formula sua visão moral sobre a natureza humana baseada no cristianismo.

Em todas as edições, há uma menção enfática quanto à concepção da "natureza humana" baseada no valor cristão da dignidade da pessoa humana. Contudo, nas edições até 1988, a "natureza humana" era apresentada como um valor, sujeito aos valores externos que "se impõem a nós, não dependem de nossas tendências, preferências" e, por sua natureza impositiva, constituem "fontes de deveres" (Brasil, 1983, p.29). O reconhecimento filosófico da "Transcendência" ocorreria na esteira do valor moral e do valor religioso, privilegiando-se desse modo "o plano ético-religioso, através dos quais se estabelece o vínculo entre a criatura humana e o Criador" (Brasil, 1983, p.29). A respeito, a doutrina mencionava Santo Agostinho: “Fizeste-nos, Senhor, Para Ti, e inquieto está o nosso coração enquanto não descansar em Ti" (Agostinho, Confissiones, Apud Brasil, 1983, p.30). Na mesma direção, a própria doutrina, ao se caracterizar, denominava-se "espiritualista" e "cristã" (Brasil, 1983, p.19).

A partir de 1988, ainda que mantidas pela doutrina, as menções diretas ao fundamento religioso são amenizadas. A própria autocaracterização foi suprimida sem que seus postulados fossem renunciados. Nesse sentido, o teísmo cristão da doutrina se alicerça na interpretação da história cultural do Brasil: situado "na vertente da cultura ocidental, de marcada influência cristã", o país "reconhece a presença imanente da divindade no ser humano, o que projeta seu destino em termos de infinito e eternidade" (Brasil, 1988, p.22; 2002, p.25; 2006a, p.5; 2009a, p.13; 2014a, p.9). Esse explícito teísmo cristão seguiu fundamentado no conceito de pessoa humana da doutrina, visto 
que "é o ser espiritual que faz da pessoa uma realidade sacra, intocável, já destinada desde o primeiro instante de sua existência a uma duração eterna" (Brasil, 1996a, p.52; 2002, p.96; 2006b, p.44; 2009b, p.52; 2014b, p.53).

A doutrina ainda manteve sua ressalva de que os valores transcendentais do cristianismo não se chocariam com outras matrizes religiosas, uma vez que "a aceitação desse humanismo teísta e cristão da cultura brasileira se faria pela assimilação dos seus valores, mesmo quando não se comungue dos dogmas de fé" (Brasil, 1988, p.22; 2002, p.25; 2006a, p.5-6; 2009a, p.13; 2014a, p.9-10). Dessa maneira, os valores do humanismo teísta-cristão se constituiriam um dever ético de toda pessoa humana da sociedade nacional, quer por serem intrínsecos à sua natureza, quer por estarem na essência da cultura ocidental. E, valendo-se da síntese do humanismo integral de Jacques Maritain, a doutrina preservou sua concepção básica de civilização cristã: a superioridade da pessoa individual sobre o grupo, a igualdade fundamental de todos os homens e a fraternidade (Brasil, 1988, p.22).

Nessa toada, o primeiro postulado humanista estaria diretamente vinculado à noção de liberdade individual e a uma visão antropocêntrica da doutrina. Trata-se da anterioridade da pessoa humana, por sua "essência de dignidade", em relação às "estruturas organizacionais da sociedade, inclusive o Estado". Ainda, da pessoa humana como "titular da soberania relacionada ao que o seu espírito cria livremente" (Brasil, 1983, p.34). A partir de 1988, a doutrina sustentava que o indivíduo, tendo em vista seu status autônomo ante qualquer grupo, poderia ser afetado pelas relações sociais, intersubjetivas, mas jamais poderia ter sua personalidade reduzida a essas relações (Brasil, 1988, p23). Nas edições seguintes, a doutrina sintetizou a premissa ao fixar em seus valores básicos que “a preeminência da pessoa se dá na medida em que é nela e por ela, exclusivamente, que se podem e devem realizar os valores supremos" (Brasil, 2002, p.25; 2006a, p.6; 2009a, p.13; 2014a, p.10). Na mesma direção, descreve a doutrina que "nascidos livres e iguais em dignidade, são os Homens capazes de (e têm direito a) buscarem, ao longo da existência, uma realização pessoal diferenciada, própria, intransponível e irredutível a padrões impostos pelo grupo" (Brasil, 1988, p.23; 2002, p.25; 2006a, p.6; 2009a, p.14; 2014a, p.10).

Igualmente, segue no sentido antropocêntrico dessa liberdade individual. Antes de 1988, a doutrina dizia-se humanista por considerar "que o homem deve ser o centro de todas as preocupações por ser ele a origem, o meio e o fim de toda a evolução sobre a Terra, o construtor e o beneficiário do seu próprio destino" (Brasil, 1983, p.19). Após 1988, a redação suprime sua menção evolutiva, mas continua considerando "o Homem, dotado de dignidade por sua natureza e seu destino transcendentes, centro de todas as preocupações" (Brasil, 2002, p.29; 2006a, p.9; 2009a, p.17; 2014a, p.15).

Quanto à igualdade fundamental de todos os homens, embora nas edições de 1975 e 1983 a doutrina não tenha dedicado atenção ao tema, nas demais edições o âmago teísta cristão se 
manifesta na fundamentação do valor de igualdade. Nesse sentido, descreve a doutrina que "a própria ideia-valor da igualdade fundamental de todos os Homens deriva da aceitação de que todos nascem iguais, dotados de uma mesma dignidade de Pessoa, sagrada e inviolável, na medida em que compartilham de um mesmo patrimônio moral e espiritual" (Brasil, 2002, p.95-96; 2006b, p.44; 2009b, p.52; 2014b, p.53).

O terceiro postulado, a fraternidade, seguiu o mesmo caminho. Antes de 1988, a doutrina traduzia esse valor como "a necessidade do amor - o mandamento síntese do Cristianismo" (Brasil, 1983, p.35). A partir de 1988, o amor é substituído pelo conceito de fraternidade, enquanto um direito-dever que se "impõe livremente" ao Homem "porque criaturas do mesmo Criador" (Brasil, 1988, p.23; 2002a, p.26; 2006a, p.6; 2009a, p.14; 2014a, p.10-11).

Em razão do "direito-dever" da fraternidade emergiria o postulado da justiça social, igualmente preservada pela doutrina após 1988. Nesse sentido, a doutrina aponta que "compondo os valores da liberdade, da igualdade e da fraternidade, sob a égide do Justo, a Justiça Social pretende superar a tensão entre liberdade e igualdade" (Brasil, 1988, p.25; 2002, p.27; 2006a, p.7; 2009a, p.15; 2014a, p.12). Esse equilíbrio, segundo a doutrina, seria possível "na medida em que propõe, como critério de sua realização, a igualdade de oportunidades, ou seja, uma igualdade de base que enseja a realização diferenciada, a competição justa e, portanto, preserva o espaço da liberdade" (Brasil, 1988, p.25; 2002, p.27; 2006a, p.7; 2009a, p.15; 2014a, p.12).

Neste ponto, verificou-se que após 1988 a doutrina suprimiu referências às consequências para liberdade face ao ideal de justiça social. Deixaram de constar na doutrina tanto a oposição a um "igualitarismo sufocante e estéril" quanto a previsão de que a liberdade deveria "sofrer as naturais limitações decorrentes dos deveres de fraternidade para com o próximo, altruísmo, da equidade e do tratamento condigno a que tem direito cada pessoa, pelo simples fato de sua condição humana" (Brasil, 1988, p.25). Assim, segundo a doutrina, justiça social seria reduzir as desigualdades "extremas e injustas", isto é, aquelas que ferem a dignidade da pessoa humana, através da promoção de igualdade de oportunidades (Brasil, 1988, p.25; 2002, p.27; 2006a, p.7; 2009a, p.15; 2014a, p.12).

A dignidade da pessoa humana - composta por liberdade individual, igualdade de oportunidades e fraternidade da justiça social - encontraria sua síntese no postulado do "Bem Comum”. Enquanto um objetivo-síntese de toda ação humana, a noção de 'Bem Comum' teria sido “delineada por São Tomás que, seguindo a tradição aristotélica, encarava a sociedade como um sistema de permuta de serviços, cada qual dentro de sua especialização, no qual se incluía a classe governante" (Brasil, 1988, p.24). Contudo, advertia a doutrina que "na concepção tomista, a sociedade é também um sistema de fins e o fim último dos governantes e dos súditos é o Bem Comum" (Brasil, 1988, p.24). Nesse sentido, conceitualmente, apesar de retirada menção à Tomás 
de Aquino, a doutrina permaneceu com idêntica definição para o ‘Bem Comum' (Brasil, 1988, p.24; 2002, p.26; 2006a, p.7; 2009a, p.14; 2014a, p.11):

"um ideal de convivência que, transcendendo a busca do bem-estar, permite construir uma sociedade onde todos, e cada um, tenham condições de plena realização de suas potencialidades como pessoa e de conscientização e prática de valores éticos, morais e espirituais".

À primeira vista, essa noção de 'Bem Comum' entraria em colisão com o valor da liberdade individual da doutrina, uma vez que a mesma prescreve a superioridade do indivíduo em relação a qualquer grupo. Contudo, argumenta a doutrina, essa liberdade individual deve se curvar à noção coletiva do 'Bem Comum'. Este teria “um sentido próprio que não se confunde com o simples agregar de vontades individuais", seria uma noção de bondade coletiva de inspiração divina que "transcende aos interesses, às aspirações e às necessidades individuais e se projeta no todo social, no conjunto dos membros da sociedade" e, consequentemente, poderia "ser identificado como distinto do bem individual, sem que este tenha de ser suprimido em nome daquele" (Brasil, 1988, p.24; 2002, p.26; 2006a, p.7; 2009a, p.14; 2014a, p.11).

Assim, resolve a doutrina, o objetivo-síntese do 'Bem Comum' superaria tanto uma concepção individualista da convivência social quanto as "concepções coletivistas, que subordinam, de modo absoluto, os valores da pessoa aos valores da coletividade" (Brasil, 1988, p.23-24; 2002, p.26; 2006a, p.6; 2009a, p.14; 2014a, p.11). Toda a sociedade, com seus indivíduos, grupos, instituições, deveriam se curvar ao 'Bem Comum', originando “determinadas obrigações de seus membros em relação ao corpo social, não apenas consubstanciadas no plano ético e moral, mas, também, no ordenamento jurídico-institucional" (2002, p.26; 2006a, p.7; 2009a, p.14; 2014a, p.11).

Nesse sentido, a doutrina é bastante clara em definir que, em termos substanciais, os valores da "preeminência da pessoa, da liberdade individual, da igualdade fundamental entre os homens e da fraternidade" são o conteúdo de sua concepção de Bem Comum, ou seja, que este seria o próprio humanismo cristão (2002, p.26; 2006a, p.7; 2009a, p.14; 2014a, p.11). Logo, o Bem Comum condiciona e norteia toda a ação humana, seja individual, seja coletiva. É na dimensão de grupo, especialmente na organização e no funcionamento da sociedade, que os efeitos desse humanismo cristão se espraiam estruturalmente na doutrina.

Da análise desses três aspectos ontológicos da doutrina da ESG podemos concluir que a escola manteve seu núcleo fundamental teológico desde a década de 70. É dizer que a instituição militar - responsável pelo monopólio da violência no Estado brasileiro - assume oficialmente o teísmo cristão como seu fundamento ideológico, marcadamente de predominância católica, mas num contexto de mobilidade do cristianismo na direção evangélica, que se reflete na própria organização militar. 


\section{Impactos potenciais da ascensão evangélica}

Como foi apresentado, o crescimento evangélico nas fileiras militares não conflitou com os fundamentos cristãos presentes da doutrina da ESG. Porém, a integração desses cristianismos não se dá de forma linear, muito menos sem tensões, pois impactam no regime de comportamento tanto do indivíduo na organização militar quanto da organização em relação aos indivíduos. Aqui estabelecemos algumas hipóteses sobre a hierarquia e disciplina, a socialização militar e a relação entre civis e militares.

No plano ideológico, um ponto de convergência seria o anticomunismo. Mais que uma ameaça ao Exército (a importância da 'Intentona Comunista' foi criada a posteriori), o anticomunismo foi uma grande arma utilizada habilmente por ele: além de possibilitar a coesão interna da corporação, o anticomunismo também favoreceu a coesão com outros setores conservadores da sociedade, algo visto no Estado Novo e em 1964 (Flores, 1992). Assim, o anticomunismo representava um inimigo comum, numa repetição da formulação estadunidense. Cunha (2020) aponta que o anticomunismo é cultivado no meio evangélico desde a década de 30, e que ensejou o apoio desse segmento ao Golpe de $1964 .{ }^{7}$ Durante a transição inacabada do regime autoritário, setores religiosos conservadores, entre eles alguns evangélicos pentecostais, se organizaram para enfrentar os movimentos sociais (identificados por eles como os herdeiros dos comunistas), que traziam para a Constituinte minorias políticas como mulheres, homossexuais, indígenas e negros (os últimos com suas religiões), e esses grupos, por sua vez, traziam pautas como o direito ao aborto, casamento entre pessoas do mesmo sexo, legalização das drogas.

Na organização social, a disciplina hierárquica é outro ponto de convergência. Tanto a caserna quanto as igrejas evangélicas desejam estabelecer uma ordem moral sobre os comportamentos que se apoiam na construção do ideal de um povo pacífico e ordeiro dentro das FA, silenciando os conflitos sociais existentes. Essa busca está presente em todos os âmbitos oficiais e informais da vida dos oficiais militares (Taschetto e Silva, 2008). Correa (2010) aponta esse mesmo traço no pentecostalismo, em especial nas áreas de pobreza e ausência do Estado, em que as igrejas exigem uma enorme disciplina (como o abandono do álcool ou drogas, ou para se alfabetizarem na leitura da Bíblia) em troca de uma opção de vida mais organizada - primeiro na vida familiar e, por conseguinte, na ordem pública.

Um terceiro ponto de convergência seria o objetivo de defesa cultural. Cunha (2020) aponta que a ascensão dos neopentecostais na política foi justificada para enfrentar ameaças culturais que representavam "a esquerda partidária, cujas bandeiras se afinavam com os ideais comunistas, as

\footnotetext{
${ }^{7}$ Assim como no seio militar, havia evangélicos contrários ao regime. Segundo o relatório da Comissão Nacional da Verdade (2014), foram presos arbitrariamente pelo menos 10 metodistas, sete presbiterianos, um pentecostal. Vários deles sofreram tortura na prisão e foram/são sobreviventes; sete evangélicos (três presbiterianos e quatro metodistas) foram mortos ou estão na lista de desaparecidos do regime; um missionário metodista estadunidense foi expulso; 14 foram exilados (sete presbiterianos, cinco metodistas, um pentecostal e um anglicano)" (Cunha, 2020, p.38).
} 
feministas, homossexuais, 'maconheiros' e 'macumbeiros'” (Cunha, 2020, p.27). De caráter ideológico, a narrativa antagônica contrastou com a integração, por parte de partidos amplamente distribuídos no espectro político, de diversas lideranças evangélicas (Cunha, 2020). No mesmo sentido, para as Forças Armadas, a esquerda partidária - e nela inclui até o Partido da Social Democracia Brasileira (PSDB) - é revanchista e insiste em impor uma falsa narrativa sobre o período da ditadura de 1964, cabalmente com a Comissão Nacional da Verdade. Aqui a defesa cultural remete à história nacional e da própria instituição militar, já que ameaças à cultura organizacional e à coesão ideológica nacional, seriam provenientes da degradação cultural, por sua vez provocada pela globalização e pelo marxismo cultural (Pinto, 2019). A ideia de defesa é acionada pelo binômio amigo e inimigo, o "eu" e o "outro". Do entendimento de que "eu e "outro" compõem extratos diferenciados, pode derivar a valoração de que um é superior a outro. No caso dos militares, superiores aos "paisanos" (Castro, 1993, p.230). Já os evangélicos, superiores aos "mundanos" (Cunha, 2020, p.24).

Para além das convergências, é possível apontar algumas hipóteses de tensão nessa relação. Uma delas é o impacto da autoridade evangélica em relação à autoridade militar no processo de socialização da organização. Cerca de $82,6 \%$ dos evangélicos têm um alto grau de religiosidade - vai ao culto uma ou mais vezes por semana, independente da denominação frequentada, o que revela um alto grau de adesão à autoridade do pastor, maior que em outras religiões (Fernandes, 2017). Para Carvalho (2005), uma identidade mais forte aumenta o grau de autonomia da organização em relação ao ambiente. As igrejas evangélicas não são organizações militares - instituições totais (Goffman, 1999, p. 17-18); tampouco têm socialização estruturalmente vocacionada para condicionar comportamentos uniformes (Carvalho, 2005; Coelho, 2000; Janowitz, 1964), mas possuem características próprias que tendem a formar comunidades relativamente estáveis e pequenas, estabelecendo laços orgânicos e uma comunidade de valores, trocas e fraternidades (Mariano, 2010, p.7). Portanto, em ambos ambientes de socialização existem muitos momentos exclusivos para seus membros, conformando fraternidades.

Um segundo ponto de tensão pode ocorrer em relação aos impedimentos disciplinares da profissão militar. ${ }^{8}$ A igreja pode absorver demandas políticas, organizacionais, emocionais, pessoais, cumprindo um papel em alguns pontos comum aos clubes militares ou a outras práticas religiosas, funcionando como redes de trocas e auxílio mútuo. ${ }^{9}$ Ademais, o militar é formado para lidar com

\footnotetext{
${ }^{8}$ Conforme a atual constituição brasileira, “ao militar são proibidas a sindicalização e a greve” (CRFB, 1988, art. 142, parágrafo terceiro, inciso IV).

${ }^{9} \mathrm{O}$ "Clube Militar - a casa da República" - foi fundado em 1887, no Rio de Janeiro, como uma associação civil, sem fins lucrativos, mas que na prática funcionou como uma instituição de organização política dos oficiais do exército. Ele foi criado após uma sucessão de conflitos entre militares e a Monarquia - episódio conhecido como "a questão militar" (1883-1887) - que culminou no golpe republicano de 1889. Na história, teve quatro presidentes que se alcançaram a presidência da república: Deodoro da Fonseca (1889-1891), Hermes da Fonseca (1910-1914), Eurico Dutra (1946-1951) e Hamilton Mourão, o atual vice-presidente (Zanini, 2020).
} 
questões de vida e morte, sua e do outro, e pode buscar uma explicação mais abrangente sobre isso. A rotina militar é repetitiva e pautada pelas tensões de um ambiente no qual impera a hierarquia e a disciplina, e no caso das escolas, a competição. O momento de culto serve tanto para as reflexões filosóficas sobre a vida humana quanto pode servir como um momento de transe, capaz de diminuir o estresse da rotina de trabalho, como em outras carreiras (Fernandes, 2017).

Quanto à hierarquia, existem ao menos dois aspectos exploratórios que merecem ser pensados - a forma de ascensão na carreira e de exercício da liderança. Quanto às promoções na carreira, de forma geral, existe uma combinação entre antiguidade (tempo de serviço) e mérito alcançado, por exemplo, através das notas nas escolas militares. Essas notas são resultado da combinação entre a avaliação vertical (feita pelos superiores) e a avaliação horizontal (feita pelos pares). As redes familiares e sociais influenciam, mas em menor grau quando comparadas ao mundo civil em geral (Autora, 2015). Questões religiosas não pareciam interferir nesse sistema. Porém, com o crescimento da pluralidade religiosa, combinada com a ascensão política do pentecostalismo, as promoções podem ser influenciadas por critérios religiosos. Uma vez que a religião proporciona ambientes de sociabilidade fortes, redes de amizade crescem em relevância. Assim, dentro da corporação militar, podem formar-se fraternidades religiosas, compostas por militares que se apoiam, se protegem e se projetam mutuamente, como em uma família tradicional, cujos 'irmãos' ascendem juntos. Segundo Mariano (2010), um princípio básico dos neopentecostais na política é que "irmão vota em irmão". Não sabemos afirmar se a lógica se repetiria para a vida profissional militar.

Já no exercício de liderança, o sincretismo e a tolerância religiosa merecem observação. ${ }^{10}$ Ao discutir alguns segmentos evangélicos, Mariano (2010, pg.7) aponta que "o propósito sectário de salvar os 'ímpios' ou de evangelizar as pessoas de outras religiões em nada contribui para o diálogo inter-religioso". Assim, cabe observar se a cultura estratégica brasileira sofrerá modificações em virtude das mudanças religiosas, pois elementos da cultura original do soldado podem interferir na sua maneira de ver e fazer a guerra (Walton, 2010). Embora não seja um ambiente de guerra, em depoimentos informais, soldados que participaram da MINUSTAH (Missão das Nações Unidas para a Estabilização no Haiti) relataram que eles, diferente de militares de outros países, não temiam os "despachos" ou outras práticas religiosas afrodescendentes produzidas por haitianos resistentes à ocupação militar, pois aquilo fazia parte da cultura do seu país original.

O Estado brasileiro, e por sua vez as Instituições públicas em geral, seguem um conjunto de rituais católicos - 'dias santos', exposição de símbolos e santidades. E agora, que a ampla hegemonia católica deu lugar a uma significativa presença evangélica, como será? Leirner (2020, p.33) relata a história da Virgem Nossa Senhora do Carmo, encontrada durante a Guerra do Paraguai, em 1864, e

\footnotetext{
${ }^{10}$ Essa noção de sincretismo não deve invisibilizar o crescente aumento da intolerância com as religiões de matriz africana, já histórico em virtude da formação social escravagista brasileira.
} 
considerada a responsável por uma importante vitória em batalha. A imagem da Virgem está guardada no Forte Coimbra (Mato Grosso) e é considerada uma milagreira pelos militares que lhe fazem promessas. Formalmente, ela recebe honras militares quando sai da unidade, como um comandante militar (tais como toque de clarinete e formação específica dos subordinados). Um militar evangélico não precisa pedir milagres, ou fazer ofertas, mas ele dificilmente seria dispensado do momento oficial, uma vez que o ritual é parte da cultura militar. Por enquanto, tem predominado o sincretismo, com eventuais tensões ou momentos comemorativos, como sepultamentos e formaturas, sendo resolvidos com atividades ecumênicas ou com a garantia de espaços separados para as práticas religiosas. ${ }^{11}$

\section{Considerações finais}

Neste artigo, buscou-se explorar possíveis impactos da ascensão evangélica em aspectos diversos do Exército brasileiro. Parte-se da constatação de que a instituição militar - responsável pelo monopólio da violência no Estado, legalmente laico - assume oficialmente o teísmo cristão como parte das suas fundamentações teóricas. Por isso, é possível identificar uma base ontológica comum entre o pensamento militar e o evangélico, ainda que o cristianismo católico seja a referência para a formulação da doutrina da ESG. Entretanto, os dados não oferecem a oportunidade de análise das denominações evangélicas em específico, o que permitiria uma discussão mais abrangente.

A tolerância religiosa parece fazer parte da formação de nossas Forças Armadas, mas está na história do cristianismo a tensão entre as autoridades estatais e religiosas. Os "santos militares" ou "santos soldados" expressam o dilema do soldado convertido: quando este percebe que as ordens emanadas das forças militares romanas conflitam com sua nova religião, as desobedece e, mesmo castigado e sob tortura, mantém sua fé acima da autoridade militar até a morte, se transformando em mártir (Woods, 2005).12 Esse dilema reaparecerá? Qual a atitude do profissional militar diante de condutas conflitantes emitidas pelo seu comandante militar e pelo seu líder espiritual?

Por enquanto, o crescimento evangélico não parece conflitar com características militares como a hierarquia e disciplina. Pelo contrário, parece alimentá-las, tornando-as mais potentes. Por exemplo, dentro das FA, já havia aqueles que as consideravam melhores que o mundo civil em geral. Quando a mentalidade militar de superioridade moral em relação aos civis se encontra com a crença de que existe um grupo de "escolhidos por Deus", ela se amplifica, pois ambos figuram

\footnotetext{
${ }^{11}$ Alencar (2010, p.5) alerta que "todas as religiões têm dificuldade de relacionamento, pois estabelecer uma relação é identificar no outro algum valor o suficiente para ele/a ser visto e ouvido. O ecumenismo é bonito na teoria, mas é piada utópica".

${ }^{12}$ Conforme Woods (2005), existem 22 santos “mártires militares”, sendo que no Brasil o mais conhecido e popular é São Jorge.
} 
Lentz, Rodrigo; Penido, Ana. Com a bíblia e com o fuzil: notas exploratórias sobre a ascensão evangélica nas forças armadas.

como grupos escolhidos dentro daqueles que já se consideram membros de uma instituição que seria, por princípio, formada pelos melhores, pelos vocacionados, pelos verdadeiros defensores do

Brasil. É um caldo de cultura perigoso no qual se encontram diferentes fundamentalismos, e a Bíblia e o fuzil não se contradizem, mas se complementam.

\section{Referências}

Alencar, Gustavo de. Protestant Groups and Social Engagement: an analysis of progressive evangelical discourse and collective action. Relig. soc., Rio de Janeiro, v. 39, n. 3, p. 173-196, Dec. 2019.

Almeida, Ronaldo de. A onda quebrada - evangélicos e conservadorismo. Cad. Pagu, Campinas, n. 50, e 175001, 2017.

AMB. Quem somos - capelanias militares. Arquidiocese Militar do Brasil, 2020. Disponível em: < https://arquidiocesemilitar.org.br/locais/exercito >. Acesso em: 20 jun. 2020.

Bohn, Simone R.. Evangélicos no Brasil: perfil socioeconômico, afinidades ideológicas e determinantes do comportamento eleitoral. Opin. Publica, Campinas, v. 10, n. 2, p. 288-338, Oct. 2004.

Brasil. Escola Superior de Guerra (Brasil). Fundamentos do método de planejamento estratégico. Rio de Janeiro: ESG, 2002.

Brasil. Escola Superior de Guerra (Brasil). Manual Básico da Escola Superior de Guerra: elementos doutrinários. Rio de Janeiro: ESG, 2006, volume 1.

Brasil. Escola Superior de Guerra (Brasil). Manual Básico da Escola Superior de Guerra: elementos doutrinários. Rio de Janeiro: ESG, 2009, volume 1.

Brasil. Escola Superior de Guerra (Brasil). Manual Básico da Escola Superior de Guerra: elementos fundamentais. Rio de Janeiro: ESG, 2014, volume 1.

Brasil. Escola Superior de Guerra (Brasil). Manual Básico. Rio de Janeiro: ESG, 1988.

Brasil. Escola Superior de Guerra (Brasil). Manual Básico. Rio de Janeiro: ESG, 1983.

Brasil. Escola Superior de Guerra (Brasil). Manual Básico. Rio de Janeiro: ESG, 1975.

Cardoso, André; Miranda, Fábio. O crescimento pentecostal e os desafios para o campo popular. Instituto Tricontinental, 11 de março de 2020. Disponível em: < https://www.thetricontinental.org/pt-pt/brasil/o-crescimentopentecostal-e-os-desafios-para-o-campo-popular/> . Acesso em: 18 jun. 2020

Carvalho, José Murilo. Forças Armadas e política no Brasil. Rio de Janeiro: Jorge Zahar, 2005.

Castro, Celso. A origem social dos militares. Novos dados para uma antiga discussão. Novos Estudos CEBRAP, nº 37, $\mathrm{p}$. 225-231, 1993.

Castro, Celso. O espírito militar: um estudo de antropologia social na Academia Militar das Agulhas Negras. Rio de Janeiro: Jorge Zahar, 2004.

Castro, Celso; Monnerat, Silvia. Por uma etnografia dos dados: a propósito de uma investigação sobre o perfil social dos militares brasileiros. Revista Sociologia, Problemas e Práticas (online) v. 91, p.1-15, 2018.

Cheaito, Karime A. B. Exército Nacional Libanês: reflexos do confessionalismo na instituição militar. Marília: Lutas Anticapital, 2019.

Coelho, Edmundo Campos. Em busca de identidade: o Exército e a política na sociedade brasileira. Rio de Janeiro: Record, 2000. 
Lentz, Rodrigo; Penido, Ana. Com a bíblia e com o fuzil: notas exploratórias sobre a ascensão evangélica nas forças armadas.

Comblin, José. A ideologia da segurança nacional: o poder militar na América Latina. 3. ed. Rio de Janeiro: Civilização Brasileira, 1980;

Correa, Marcos Sá. Uma opção de vida mais organizada para os pobres. Revista do Instituto Humanitas Unisinos, São Leopoldo, ed. 329, p.19-21, 2010.

Cunha, Magali do Nascimento. A Explosão Gospel. Um olhar das ciências humanas sobre o cenário evangélico contemporâneo. Rio de Janeiro: Mauad, 2007.

Cunha, Magali do Nascimento. Religião e Política: uma visão protestante. In Tostes, Angelica e Ribeiro, Cláudio, Religiões e Intervenção Política: Múltiplos Olhares. São Paulo: Editora Recriar, 2020.

Farias, Oswaldo Cordeiro de. Razões que levaram o governo a pensar na organização da escola superior de guerra. Revista da Escola Superior de Guerra, [S.1.], n. 20, p. 133-147, dec. 1991.

Fernandes, Marco. Psicoterapia Popular do Espírito Santo: hipóteses sobre sobre o sucesso pentecostal na periferia de cidades periféricas. Revista Margem Esquerda, p. 92-114, 2017.

Finer, Samuel. The man on horseback. New Brunswick: Transaction Publishers, 2002.

Flores, Mário César. Bases para uma Política Militar. Campinas: UNICAMP, 1992.

Giumbelli, Emerson. Cultura pública: evangélicos y su presencia en la sociedad brasileña. Sociedad y Religion №40, Vol XXIII (2013), pp. 13-43.

Goffman, Erving. Manicômios, prisões e conventos. Tradução de Dante Moreira Leite. 7. edição. São Paulo: Perspectiva, 1999.

Huntington, Samuel P. O soldado e o Estado: teoria política das relações entre civis e militares. Rio de Janeiro: Biblioteca do Exército, 1996.

IBGE - Instituto Brasileiro de Geografia e Estatística. Censo Demográfico 2010. Resultados gerais da amostra. Rio de Janeiro: IBGE, 2012.

ISCM. História - linha do tempo. Irmandade da Santa Cruz dos Militares, sem data. Disponível em: <http://www.iscm.org.br/historia/linha-do-tempo/>. Acesso em: 19 jun. 2020.

Janowitz, Morris. The military in the political development of new nations: an essay in comparative analysis. Chicago, Chicago University Press, 1964.

Leirner, Piero. Mini-manual da hierarquia militar: uma perspectiva antropológica. Col.IndePub/SC. São Carlos, 2020.

Lentz, Rodrigo. O pensamento político dos militares brasileiros: a doutrina de "segurança nacional" revisitada (1930-1985). Revista da Escola Superior de Guerra, [S.1.], v. 34, n. 70, p. 39-71, apr. 2019.

Mafra, Carla. Os evangélicos no Brasil. Editora Zahar: Rio de Janeiro, 2001.

Mariano, Ricardo. Expansão e ativismo político de grupos evangélicos conservadores: secularização e pluralismo em debate. Civitas, Rev. Ciênc. Soc., Porto Alegre, v. 16, n. 4, p. 708-726, Dec. 2016.

Mariano, Ricardo. O pentecostalismo no Brasil, cem anos depois. Uma religião dos pobres. Revista do Instituto Humanitas Unisinos, São Leopoldo, ed. 329, p.8-11, 2010.

Matos, Alderi S. Pentecostalismo: traços históricos. Revista do Instituto Humanitas Unisinos, São Leopoldo, ed. 329, p.12-14, 2010.

Miguel, Luís Felipe. Para entender o golpe. Blog Boitempo, 1set.2016. Disponível em: <https://blogdaboitempo.com.br/2016/09/01/para-entender-o-golpe/>. Acesso em: 21 jun. 2020.

Miguel, Luís Felipe; BIROLI, Flávia; MARIANO, Rayani. O direito ao aborto no debate legislativo brasileiro: a ofensiva conservadora na Câmara dos Deputados. Opin. Publica, Campinas, v. 23, n. 1, p. 230-260, Apr. 2017. 
Lentz, Rodrigo; Penido, Ana. Com a bíblia e com o fuzil: notas exploratórias sobre a ascensão evangélica nas forças armadas.

Oliveira, Eliézer Rizzo (Org.). Militares: pensamento e ação política. Campinas, Papirus Livraria Editora, 1987. Coleção "Forças Armadas e Sociedade", Volume n.1

Oro, Ari Pedro. A política da Igreja Universal e seus reflexos nos campos religioso e politico brasileiros. Rev. bras. Ci. Soc., São Paulo, v. 18, n. 53, p. 53-69, out. 2003.

Panotto, Nicolás. Campo evangélico y sociedad civil: sobre los procesos de minoritización y el desplazamiento de matrices analíticas. Relig. soc., Rio de Janeiro, v. 40, n. 1, p. 21-42, Jan. 2020

Penido, Ana. (2015), Profissionalização e educação militar: um estudo a partir da Academia Militar das Agulhas Negras. Dissertação (Mestrado em Estudos Estratégicos), Universidade Federal Fluminense, Niterói.

Penido, Ana; Kalil Mathias, Suzeley; Rodrigues, Jorge. (2020), As forças armadas no governo Bolsonaro. Instituto Tricontinetal de Pesquisa Social, 14 abr. 2020. Disponível em: $<$ https://www.thetricontinental.org/ptpt/brasil/as-forcas-armadas-no-governo-bolsonaro/>. Acesso em: 21 jun. 2020.

Penido, Ana; Lentz, Rodrigo. (2020), O partido militar e as FFAA no governo Bolsonaro - parte III. Instituto Tricontinetal de Pesquisa Social, 22 jun. 2020. Disponível em: $<$ https://www.thetricontinental.org/pt-pt/brasil/opartido-militar-e-as-ffaa-no-governo-bolsonaro-parte-iii/>. Acesso em: 22 jun. 2020.

Prandi, Reginaldo; Santos, Renan William dos. Quem tem medo da bancada evangélica? Posições sobre moralidade e política no eleitorado brasileiro, no Congresso Nacional e na Frente Parlamentar Evangélica. Tempo soc., São Paulo, v. 29, n. 2, p. 187-214, May 2017.

Rodrigues, Guilherme Alberto; Fuks, Mario. Grupos sociais e preferência política: o voto evangélico no Brasil. Rev. bras. Ci. Soc., São Paulo, v. 30, n. 87, p. 115-128, Feb. 2015.

Santos, Everton Rodrigo. Poder e Dominação: a Escola Superior de Guerra (1974-1989). Porto Alegre: Sulina, 2010.

Seto, Guilherme. Slogan de Bolsonaro foi inspirado em brado de paraquedistas militares. Folha de São Paulo, 24 out. 2018. Disponível em: https://www1.folha.uol.com.br/poder/2018/10/slogan-de-bolsonaro-foi-inspirado-embrado-de-paraquedistas-militares.shtml . Acesso em: 18 jun. 2020.

Stepan, Alfred. O que estão pensando os militares. Novos Estudos CEBRAP, São Paulo, v.2, p.2-7, jul.1983.

Stepan, Alfred. Os militares na política. Rio de Janeiro: Artenova, 1975.

Taschetto, L. R.; Silva, R. A. Direitos Humanos e Polícia. Civitas, Porto Alegre, RS. v. 8, p. 454-465, 2008.

Walton, C. Dale. The Second Nuclear Age: nuclear weapons in the Twenty-first Century. In Strategy in the Contemporary World - third edition. New York: Oxford, 2010.

Woods, David. The Military Martyrs. Dept. of Classics, University College Cork, Ireland, abr. 2005. Disponível em: < https://www.ucc.ie/archive/milmart/index.html>. Acesso em 21 jun.2020.

Zanini, Fábio. Após anos de ostracismo, Clube Militar volta ao centro do poder com Bolsonaro. Folha de São Paulo, 10 abr. 2019. Disponível em: <https://saidapeladireita.blogfolha.uol.com.br/2019/04/10/apos-anos-de-ostracismo-clubemilitar-ve-sua-ideias-triunfarem-com-bolsonaro/>.Acesso em: 21 jun. 2020. 